\title{
Impact of MAGE-A antigens on taxane response in oral squamous cell carcinoma
}

\author{
URS D.A. MÜLLER-RICHTER ${ }^{1}$, ALBERT DOWEJKO ${ }^{2}$, OLIVER DRIEMEL ${ }^{2}$, \\ TOBIAS REUTHER ${ }^{1}$, TORSTEN E. REICHERT ${ }^{2}$ and ALEXANDER C. KÜBLER ${ }^{1}$
}

\author{
${ }^{1}$ Department of Oral and Maxillofacial Plastic Surgery, University Hospital Würzburg, 97070 Würzburg; \\ ${ }^{2}$ Department of Oral and Maxillofacial Surgery, University of Regensburg, 93053 Regensburg, Germany
}

Received April 10, 2009; Accepted September 28, 2009

DOI: 10.3892/ol_00000033

\begin{abstract}
MAGE-A antigens are a subgroup of cancer/testis antigens that are exclusively expressed in malignant cells. Only scarce information on the function of MAGE-A antigens is available. There is some evidence that they may influence the response to chemotherapeutic drugs. This study aimed to evaluate the impact of the MAGE-A antigen subgroups MAGE-A2, -A3, -A4 and -A6 on oral squamous cell carcinoma cell lines treated with docetaxel and paclitaxel. Five oral squamous cell carcinoma cell lines were characterized for their quantitative expression of MAGE-A2, -A3, -A4 and -A6. The cell lines were treated with concentrations ranging from 0.025 to $0.8 \mu \mathrm{M}$ of docetaxel and paclitaxel. The amount of viable cells after 24 and $48 \mathrm{~h}$ was measured. The measurements were statistically correlated with MAGE-A expression. All cell lines responded to docetaxel and paclitaxel. One cell line showed a statistically significant weaker response to the taxane treatment. This cell line was the only one that expressed MAGE-A4. MAGE-A4 has a statistically significant impact on the tumour response to docetaxel and paclitaxel in oral squamous cell carcinoma. This may influence treatment options and the course of the disease. Therefore, patients should be evaluated for MAGE-A4 expression before treatment with taxanes.
\end{abstract}

\section{Introduction}

MAGE-A antigens are a subgroup of cancer/testis antigens. They are exclusively found in malignant tumours except in rare cases (e.g., testes, placenta) (1). To date, many tumour entities have been tested for their MAGE-A expression (2). Oral squamous cell carcinomas were found to express MAGE-A antigens (3). MAGE-A antigens consist of 12 different antigen subgroups that are expressed in different constellations and amounts in tumour

Correspondence to: Dr Urs Müller-Richter, Department of Oral and Maxillofacial Plastic Surgery, University Hospital Würzburg, Pleicherwall 2, 97070 Würzburg, Germany

E-mail: mueller_u2@klinik.uni-wuerzburg.de

Key words: MAGE-A antigens, chemotherapy, taxanes, oral squamous cell carcinoma, tumour antigens cells (3). MAGE-A antigens are able to induce T-cell and humoral immune response. The functions and role of the MAGE-A antigens (e.g., in cell differentiation or cell cycle) remain unknown (4,5). Notably, they are expressed in stem cells but not in differentiated fetal keratinocytes (6). In adult keratinocytes they are no longer detected. This supports the presumption of a function of MAGE-A antigens in cell differentiation. Recent studies have shown a possible link between MAGE-A expression in tumour cells (e.g., gastric carcinoma, breast cancer or ovarian carcinoma) and the response rate to anti-neoplastic treatments with taxanes (paclitaxel and docetaxel) $(7,8)$.

Taxanes are chemotherapeutic agents that prevent the depolymerization of microtubules and subsequently interrupt cell division. Paclitaxel and docetaxel share the same basic molecular structure but differ in their side chains. Docetaxel has nearly twice the affinity to microtubules compared with paclitaxel (9). This results, in the majority of cases, in higher cytotoxicity in certain tumours (10).

To investigate the impact of MAGE-A antigen subgroups on the response to anti-neoplastic treatment with taxanes in oral squamous cell carcinoma, five tumour cell lines were analyzed for quantitative MAGE-A expression. These cell lines were characterized in a previous study regarding their quantitative expression of MAGE-A2, -A3, -A4, -A6 and -A10 (referenced to an adult keratinocyte cell line) (11). The cell lines were treated with different concentrations of docetaxel and paclitaxel, and the measure of apoptosis in viable tumour cells was determined after $24 \mathrm{~h}$ with respect to $48 \mathrm{~h}$. These measurements were compared with the expression of the MAGE-A subgroups. A significant correlation between MAGE-A subgroup expression and the apoptosis rate may indicate a reduced response rate to taxane treatment resulting in an impact on cancer treatment.

\section{Materials and methods}

Tumour cell lines. Measured levels of MAGE-A subgroup expression were normalized to the adult keratinocyte cell line (NHEK) (11). The values are given in arbitrary units (a.u.).

PCI 68-1 (root of tongue carcinoma, pT4NOMOG1). In this cell line, only MAGE-A3 was significantly increased. However, the expression level of 2.97 a.u. was not very high. 
Table I. The decrease in viable cells according to time elapsed and concentration of docetaxel.

\begin{tabular}{|c|c|c|c|c|c|c|c|c|c|c|}
\hline \multirow{2}{*}{$\begin{array}{l}\text { Docetaxel } \\
\qquad \mu \mathrm{M}\end{array}$} & \multicolumn{2}{|c|}{ PCI 68-1 } & \multicolumn{2}{|c|}{ PCI 1-1 } & \multicolumn{2}{|c|}{ PCI 52} & \multicolumn{2}{|c|}{ PCI 9-1 } & \multicolumn{2}{|c|}{ PCI 13-1 } \\
\hline & $24 \mathrm{~h}$ & $48 \mathrm{~h}$ & $24 \mathrm{~h}$ & $48 \mathrm{~h}$ & $24 \mathrm{~h}$ & $48 \mathrm{~h}$ & $24 \mathrm{~h}$ & $48 \mathrm{~h}$ & $24 \mathrm{~h}$ & $48 \mathrm{~h}$ \\
\hline 0.000 & 100.00 & 100.00 & 100.00 & 100.00 & 100.00 & 100.00 & 100.00 & 100.00 & 100.00 & 100.00 \\
\hline 0.025 & 73.30 & 42.21 & 61.57 & 39.67 & 89.28 & 75.15 & 60.14 & 30.40 & 67.53 & 26.47 \\
\hline 0.050 & 59.36 & 30.59 & 58.47 & 23.11 & 83.76 & 71.81 & 52.73 & 24.65 & 51.91 & 11.30 \\
\hline 0.100 & 56.97 & 22.81 & 55.25 & 17.40 & 71.42 & 65.23 & 49.38 & 19.68 & 43.00 & 7.50 \\
\hline 0.200 & 53.60 & 20.77 & 54.29 & 14.53 & 69.23 & 55.90 & 46.33 & 19.01 & 40.69 & 4.15 \\
\hline 0.400 & 52.40 & 20.81 & 54.52 & 16.86 & 65.12 & 50.84 & 49.13 & 14.88 & 38.01 & 3.94 \\
\hline 0.800 & 53.45 & 18.44 & 50.63 & 14.76 & 65.84 & 47.47 & 42.71 & 13.67 & 38.34 & 3.08 \\
\hline$\Delta^{\mathrm{a}}$ & 46.55 & 81.56 & 49.37 & 85.24 & 34.16 & 52.53 & 57.29 & 86.33 & 61.66 & 96.92 \\
\hline
\end{tabular}

The mean values are calculated from nine different measurements. ${ }^{a} \Delta$, percentage of cell loss with $0.8 \mu \mathrm{M}$ docetaxel. Bold, statistically significant measures.

Table II. The decrease of viable cells according to time elapsed and concentration of paclitaxel.

\begin{tabular}{|c|c|c|c|c|c|c|c|c|c|c|}
\hline \multirow{2}{*}{$\begin{array}{l}\text { Paclitaxel } \\
\qquad \mu \mathrm{M}\end{array}$} & \multicolumn{2}{|c|}{ PCI 68-1 } & \multicolumn{2}{|c|}{ PCI 1-1 } & \multicolumn{2}{|c|}{ PCI 52} & \multicolumn{2}{|c|}{ PCI 9-1 } & \multicolumn{2}{|c|}{ PCI 13-1 } \\
\hline & $24 \mathrm{~h}$ & $48 \mathrm{~h}$ & $24 \mathrm{~h}$ & $48 \mathrm{~h}$ & $24 \mathrm{~h}$ & $48 \mathrm{~h}$ & $24 \mathrm{~h}$ & $48 \mathrm{~h}$ & $24 \mathrm{~h}$ & $48 \mathrm{~h}$ \\
\hline 0.000 & 100.00 & 100.00 & 100.00 & 100.00 & 100.00 & 100.00 & 100.00 & 100.00 & 100.00 & 100.00 \\
\hline 0.025 & 103.25 & 87.73 & 92.35 & 90.76 & 112.19 & 95.07 & 110.96 & 91.30 & 95.28 & 95.26 \\
\hline 0.050 & 85.49 & 56.15 & 82.88 & 68.13 & 110.18 & 87.93 & 115.68 & 55.91 & 80.13 & 67.57 \\
\hline 0.100 & 71.18 & 38.79 & 67.57 & 41.05 & 93.72 & 85.37 & 95.41 & 30.00 & 54.19 & 34.11 \\
\hline 0.200 & 72.80 & 29.35 & 51.98 & 18.21 & 93.50 & 71.42 & 75.98 & 20.22 & 41.05 & 11.35 \\
\hline 0.400 & 62.01 & 27.99 & 41.45 & 8.44 & 84.14 & 69.80 & 76.51 & 15.37 & 34.27 & 5.36 \\
\hline 0.800 & 62.44 & 24.23 & 34.71 & 6.52 & 79.41 & 63.23 & 70.59 & 12.72 & 33.08 & 2.20 \\
\hline$\Delta^{\mathrm{a}}$ & 37.56 & 75.77 & 65.29 & 93.48 & 20.59 & 36.77 & 29.41 & 87.28 & 66.92 & 97.80 \\
\hline
\end{tabular}

The mean values are calculated from nine different measurements. ${ }^{a} \Delta$, percentage of cell loss with $0.8 \mu \mathrm{M}$ paclitaxel. Bold, statistically significant measures.

PCI 1-1 (larynx carcinoma, pT2NOMOG2). This cell line expressed 3 different MAGE-A antigens (A2, A3 and A6). MAGE-A2 and -A3 were expressed at a moderate level (A2, 9.21 a.u.; A3, 9.76 a.u.), and MAGE-A6 was expressed at a high level (64.54 a.u.).

PCI 52 (larynx carcinoma, pT2NOMOG2). The expression profile of this cell line showed the most increased expression of MAGE-A antigen subgroups. MAGE-A2, -A3, -A4 and -A6 were increased. PCI 52 is also the only cell line examined that showed significant expression of MAGE-A4 (15.96 a.u.). PCI 52 exhibited the highest expression level of MAGE-A2 (15.39 a.u.) among the cell lines examined. The expression of MAGE-A6 achieved the same level and reached 18.31 a.u. The amount of MAGE-A3 expression was the lowest (3.49 a.u.).

PCI 9-1 (root of tongue carcinoma, pT4N3MOG2). This cell line also expressed a group of MAGE-A antigens. As with PCI
1-1, this cell line highly expressed MAGE-A2, -A3 and -A6 antigen subgroups. MAGE-A2 reached an expression level of 10.67 a.u., MAGE-A3, 8.88 a.u. and MAGE-A6, 85.86 a.u. (the highest value measured among the cell lines examined).

PCI 13-1 (oral squamous cell carcinoma, pT4N1M0G3). Similar to cell line 9-1, MAGE-A antigen subgroups A2, A3 and A6 were significantly expressed. The expression levels were also comparable to cell line 9-1. MAGE-A2 showed an expression of 11.46 a.u.; MAGE-A3, 9.94 a.u. (the highest value measured among the cell lines) and MAGE-A6, 62.79 a.u.

Cell cultures. The cell lines were grown at $37^{\circ} \mathrm{C}$ and $5 \% \mathrm{CO}_{2}$ in Dulbecco's modified Eagle's medium (DMEM low glucose; Invitrogen, Karlsruhe, Germany; 100 mg/l D-glucose, 4 mMl glutamine, $110 \mathrm{mg} / \mathrm{l}$ sodium pyruvate) with $10 \%$ fetal calf serum, $100 \mathrm{IU} / \mathrm{ml}$ penicillin and $100 \mathrm{mg} / \mathrm{ml}$ streptomycin (PromoCell, Heidelberg, Germany). 
Cytotoxicity test. The chemosensitivity of the cultured cell lines after application of docetaxel and paclitaxel was measured with CellTiter Aqueous One Solution Cell Proliferation Assay (Promega Corp., Madison, WI, USA) according to the manufacturer's instructions. The test measures colorimetrically the count of viable cells. It uses a tetrazolium compound that is metabolized to formazan in mitochondria. Formazan is measured by absorption, and its quantity is proportional to the number of viable cells. For the cytotoxicity test, 1000 cells of each cell line examined were seeded in triplicate on 96-well plates (Corning, NY, USA) in $100 \mu \mathrm{l}$ phenol-red free DMEM-medium and incubated overnight. The following day, six different concentrations $(0.025,0.05,0.1,0.2,0.4$ and $0.8 \mu \mathrm{M})$ of paclitaxel soluted in DMSO and docetaxel soluted in ethanol (both from Sigma, Germany) were added to the seeded cells. After 24 and $48 \mathrm{~h}$ of incubation in each cell medium, $20 \mu \mathrm{l}$ MTS solution [3-(4,5-dimethylthiazol-2-yl)-5-(3-carboxymethoxyphenyl)2-(4-sulfophenyl)-2H-tetrazolium] was added. After an additional $4 \mathrm{~h}$, absorption at $450 \mathrm{~nm}$ was measured with the microplate reader Infinite ${ }^{\circledR}$ F200 (Tecan, Männedorf, Switzerland). This resulted in three measurements of three different cell cultures $(n=9)$. A corresponding cell line that was not treated with taxanes was measured as a control. The values measured were normalized to those of the untreated cell line.

Statistical analysis. The mean values of the number of viable cells corresponding to the concentration of taxanes used were calculated using a two-dimensional fit curve [equation: $\mathrm{f}=\mathrm{y} 0+(\mathrm{a} * \mathrm{~b}) /(\mathrm{b}+\mathrm{x})]$ using Excel 2007 (Microsoft, USA) To predict the accuracy of the measured values, the coefficient of determination $\mathrm{R}^{2}$ was calculated. A value $\geq 0.7$ represented a good approximation. The percentage of decrease in viable cells after application of $0.8 \mu \mathrm{M}$ of the chemotherapeutic drug compared with the untreated cells was named $\Delta$.

To detect statistically significant differences between the single cell lines, univariate analyses were performed. These differences were further statistically correlated with the amounts of viable cells after $24 \mathrm{~h}$ with respect to $48 \mathrm{~h}$.

\section{Results}

The cell lines showed a favorable response to docetaxel and placlitaxel. As estimated, the number of viable cells decreased exponentially with higher concentrations of docetaxel or paclitaxel and with time elapsed (Tables I and II). No statistical correlation between tumour size, metastases or grade of the primary tumours of which the cell lines were established was found.

The cell lines showed a similar exponential decrease in viable cells when plotting the viability to taxane concentration. In four out of the five cell lines (PCI 68-1, PCI 1-1, PCI 9-1 and PCI 13-1) similar levels of cell loss were achieved. This cell loss is represented by Delta, as mentioned above.

The Deltas for $0.8 \mu \mathrm{M}$ docetaxel and $24 \mathrm{~h}$ were: PCI 68-1, 46.55; PCI 1-1, 49.37; PCI 9-1, 57.29 and PCI 13-1, 61.66 (Fig. 1). After $48 \mathrm{~h}$ of docetaxel incubation, the Deltas were: PCI 68-1, 81.56; PCI 1-1, 85.24; PCI 9-1, 86.33 and PCI 13-1, 96.92 (Fig. 2).

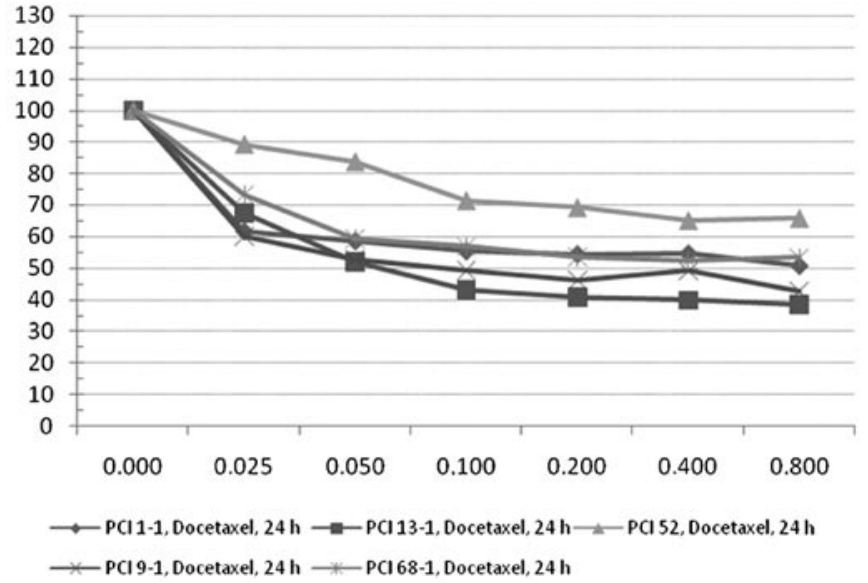

Figure 1. Exponential decrease of viable cells at different concentrations of docetaxel within $24 \mathrm{~h}$; $\mathrm{x}$-axis, increasing concentrations of docetaxel in $\mu \mathrm{M}$ and $y$-axis, percentage of viable cells.

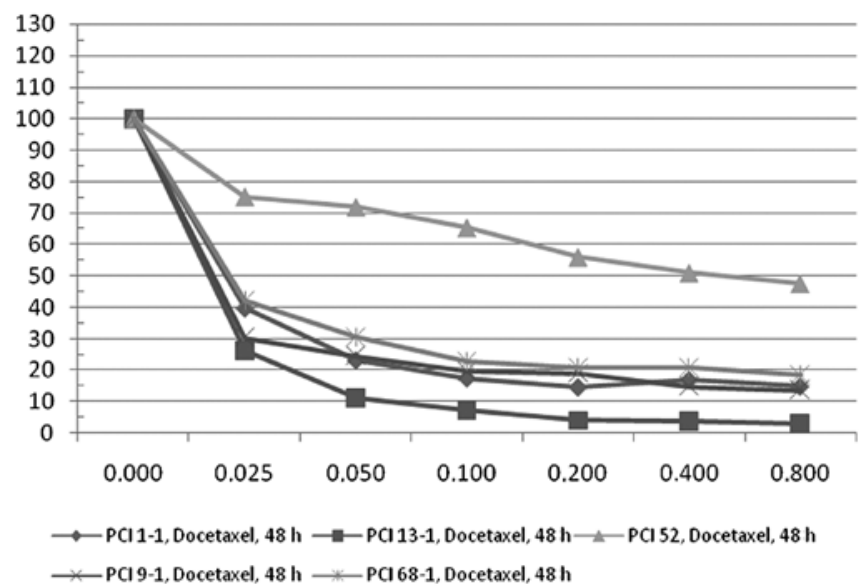

Figure 2. Exponential decrease of viable cells at different concentrations of docetaxel within $48 \mathrm{~h}$. Of note is the significantly lower decrease of viable cells in the cell line PCI 52; $\mathrm{x}$-axis, increasing concentrations of docetaxel in $\mu \mathrm{M}$ and $\mathrm{y}$-axis, percentage of viable cells.

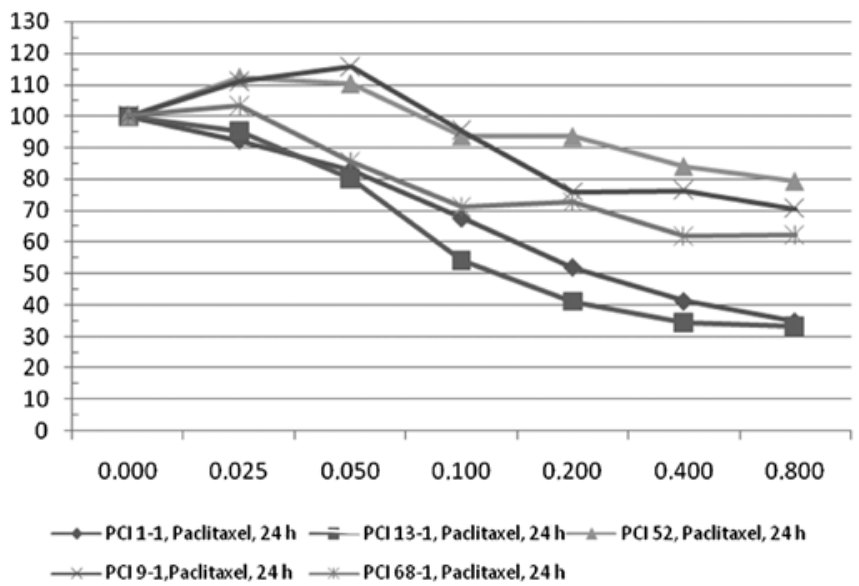

Figure 3. The relatively homogeneous distribution of cell decrease between the cell lines. No cell line significantly differed in the number of viable cells after $24 \mathrm{~h}$ of paclitaxel application; $\mathrm{x}$-axis, increasing concentrations of paclitaxel in $\mu \mathrm{M}$ and $\mathrm{y}$-axis, percentage of viable cells. 


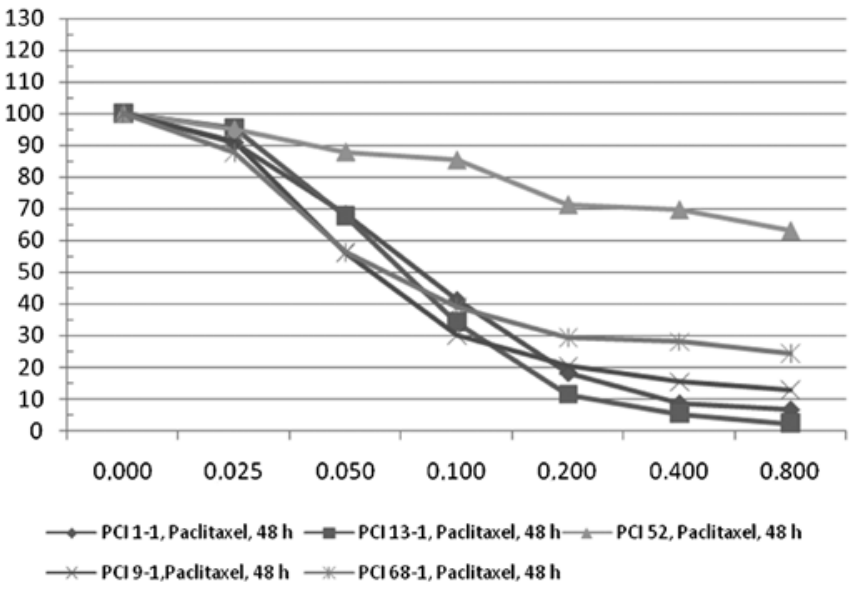

Figure 4. Significantly reduced decrease of viable cells within $48 \mathrm{~h}$ of paclitaxel incubation. The decrease at $0.8 \mu \mathrm{M}$ was less than half of the next most viable cell line (PCI 68-1); x-axis, increasing concentrations of paclitaxel in $\mu \mathrm{M}$ and $\mathrm{y}$-axis, percentage of viable cells.

In contrast to the four cell lines, PCI 52 exhibited different characteristics. After $24 \mathrm{~h}$ of docetaxel application, $\Delta$ was 34.16 and after $48 \mathrm{~h}$ only 52.53. These results were statistically significant $(\mathrm{p}<0.05)$.

When applying paclitaxel to the cell lines, the results were similar to docetaxel. $\Delta$ for $0.8 \mu \mathrm{M}$ paclitaxel and $24 \mathrm{~h}$ were: PCI 68-1, 37.56; PCI 1-1, 65.29; PCI 9-1, 29.41 and PCI 13-1, 66.92 (Fig. 3). After $48 \mathrm{~h}$ of paclitaxel incubation $\Delta$ was: PCI 68-1, 75.77; PCI 1-1, 93.48; PCI 9-1, 87.28 and PCI 13-1, 97.80 (Fig. 4). The fifth cell line PCI 52 again showed a different response rate. $\Delta$ was $20.59(24 \mathrm{~h})$ and 36.77 (48 h). These results were also statistically significant $(\mathrm{p}<0.05)$.

The cell line PCI 52 exhibited a statistically significant difference in the expression profile of the MAGE-A antigens compared to the other cell lines $(\mathrm{p}<0.05)$. It is the only cell line among the five analyzed that expressed the MAGE-A4 antigen. PCI 52 expressed MAGE-A2, -A3 and -A6 which were also expressed in the other cell lines examined. Therefore, we propose that its differential behavior is correlated with its MAGE-A4 expression.

\section{Discussion}

The function of the MAGE-A antigens remains unknown. There is scarce information on the impact of the MAGE-A antigen subgroup expression in tumour cells on treatment with anti-neoplastic agents and the course of cancer. Additionally, little is known about the expression of the single antigen subgroups (MAGE-A1 to -A12) in different tumour entities. Only five reported studies have investigated at least four subtypes of MAGE-A antigens in wild-type oral squamous cell carcinoma $(3,12-15)$. In light of their exclusive appearance in malignant cells and immunogenicity and their use as possible targets of immunotherapy, further investigation is warranted.

This is the first report involving the reduced response rate of oral squamous cell carcinoma to chemotherapeutic agents (taxanes) correlating with the expression of the MAGE-A4 subgroup. A recent study investigating the influence of cancer/testis antigens on T-cell-mediated immune response in patients suffering from medulloblastoma also found an impact of MAGE-A expression level on the response to chemotherapeutic drugs cisplatin and etoposide (16). These findings are relevant to oral squamous cell carcinoma, since cisplatin is one of the pillars of anti-neoplastic treatment of this tumour. It is also used in adjuvant radio-chemotherapy as well as in palliative settings. One study demonstrated a higher response rate to paclitaxel in gastric cancer patients expressing the MAGE-A1 antigen subgroup (7). Duan et al found resistance to paclitaxel and doxorubicin in an ovarian cancer cell line expressing MAGE and GAGE antigens (8). However, they did not further elucidate the roles of the specific MAGE-A antigen subgroups.

Our findings and these studies confirm the impact of MAGE-A antigen subgroups on response to chemotherapeutic drugs. Identifying and evaluating this impact is crucial for the prognosis and survival of patients suffering from oral squamous cell carcinoma. Considering the impact of tumour resistance to taxanes compared with their occasional lifethreatening side effects such as neutropenia, fluid retention, neuropathia and toxic effects, managing this impact is crucial. Further studies that characterize cell lines in regards to their MAGE-A expression profile and impact on commonly used chemotherapeutic drugs (e.g., taxanes, platin drugs, 5-fluorouracil) are necessary. These studies will help to improve the anti-neoplastic treatment of cancer patients, minimize unnecessary side effects and improve survival.

\section{References}

1. Serrano A, Lethe B, Delroisse JM, Lurquin C, de Plaen E, Brasseur F, Rimoldi D and Boon T: Quantitative evaluation of the expression of MAGE genes in tumors by limiting dilution of cDNA libraries. Int J Cancer 83: 664-669, 1999.

2. Jungbluth AA, Busam KJ, Kolb D, Iversen K, Coplan K, Chen YT, Spagnoli GC and Old LJ: Expression of MAGEantigens in normal tissues and cancer. Int J Cancer 85: 460-465, 2000.

3. Ries J, Schultze-Mosgau S, Neukam F, Diebel E and Wiltfang J: Investigation of the expression of melanoma antigen-encoding genes (MAGE-A1 to -A6) in oral squamous cell carcinomas to determine potential targets for gene-based cancer immunotherapy. Int J Oncol 26: 817-824, 2005.

4. Ohman Forslund $\mathrm{K}$ and Nordqvist K: The melanoma antigen genes - any clues to their functions in normal tissues? Exp Cell Res 265: 185-194, 2001.

5. Xiao $\mathrm{J}$ and Chen HS: Biological functions of melanomaassociated antigens. World J Gastroenterol 10: 1849-1853, 2004.

6. Muller-Richter UD, Dowejko A, Zhou W, Reichert TE and Driemel O: Different expression of MAGE-A-antigens in foetal and adult keratinocyte cell lines. Oral Oncol 44: 628-633, 2008.

7. Suzuki T, Yoshida K, Wada Y, Hamai Y, Sentani K, Oue N and Yasui W: Melanoma-associated antigen-A1 expression predicts resistance to docetaxel and paclitaxel in advanced and recurrent gastric cancer. Oncol Rep 18: 329-336, 2007.

8. Duan Z, Duan Y, Lamendola DE, Yusuf RZ, Naeem R, Penson RT and Seiden MV: Overexpression of MAGE/GAGE genes in paclitaxel/doxorubicin-resistant human cancer cell lines. Clin Cancer Res 9: 2778-2785, 2003.

9. Diaz JF and Andreu JM: Assembly of purified GDP-tubulin into microtubules induced by taxol and taxotere: reversibility, ligand stoichiometry and competition. Biochemistry 32: 2747-2755, 1993.

10. Hanauske AR, Degen D, Hilsenbeck SG, Bissery MC and von Hoff DD: Effects of taxotere and taxol on in vitro colony formation of freshly explanted human tumor cells. Anticancer Drugs 3: 121-124, 1992. 
11. Müller-Richter UDA, Dowejko A, Reuther T, Kleinheinz J, Reichert TE and Driemel O: Analysis of expression profiles of MAGE-A antigens in oral squamous cell carcinoma cell lines. Head Face Med 5: 10, 2009.

12. Ries J, Vairaktaris E, Mollaoglu N, Wiltfang J, Neukam FW and Nkenke E: Expression of melanoma-associated antigens in oral squamous cell carcinoma. J Oral Pathol Med 37: 88-93, 2008.

13. Figueiredo DL, Mamede RC, Proto-Siqueira R, Neder L, Silva WA Jr and Zago MA: Expression of cancer testis antigens in head and neck squamous cell carcinomas. Head Neck 28: 614-619, 2006.

14. Lee KD, Lee HH, Joo HB, Lee HS, Yu TH, Chang HK, Jeon $\mathrm{CH}$ and Park JW: Expression of MAGE A 1-6 mRNA in sputa of head and neck cancer patients - a preliminary report. Anticancer Res 26: 1513-1518, 2006.
15. Lee KD, Eura M, Ogi K, Nakano K, Chikamatsu K, Masuyama K and Ishikawa T: Expression of the MAGE-1, -2, -3, -4 and -6 genes in non-squamous cell carcinoma lesions of the head and neck. Acta Otolaryngol 116: 633-639, 1996.

16. Kasuga C, Nakahara Y, Ueda S, Hawkins C, Taylor MD, Smith CA and Rutka JT: Expression of MAGE and GAGE genes in medulloblastoma and modulation of resistance to chemotherapy. Laboratory investigation. J Neurosurg Pediatr 1: 305-313, 2008 